\title{
18
}

\section{THE POWER OF OPEN EDUCATIONAL TECHNOLOGY}

\author{
Martin Dougiamas
}

\section{A Learning World}

Our information and communications technology define us as a species. From a slow start communicating by drums, cave paintings and smoke signals, we've rapidly learned how to use the materials around us to capture, store, transmit and consume the information we generate together. Our ability to learn together is one of the main drivers behind the exponential growth we see in our ability to control the world around us, and to constantly push ourselves further and deeper in every direction.

Education is, of course, something we do all the time, in our interactions with society around us, mediated by technology and culture. The formal education that happens in schools and universities gives us certain efficiencies to make sure that the "things we find important" at some level are learned in a more-or-less consistent way, creating some commonality as citizens of more stable societies.

As electronic technology started to gain popularity in the last few decades, we've seen three main effects on our general education.

1. Schools, universities and other organizational learning programs have been "moving online" using Learning Management Systems (LMS) and other similar platforms. In general, this has meant an almost direct replication of brickand-mortar classrooms into "digital classrooms," with very similar structures and practices, but with increased efficiency and flexibility.

2. A rise in learning via social media and direct person-to-person messaging, mediated by AI algorithms, on advertising-funded, profit-focused, surveillance-based platforms like Facebook, YouTube, Twitter, WhatsApp, etc. This has resulted in an explosion of just-in-time learning but has also created 
"filter bubbles," "viral information," "fake news," "radicalization," “celebrity culture," "democratic failure," "meme simplification," "disconnection from reality," "anxiety" and many other undesirable outcomes.

3. A rise in short online courses, outside of traditional institutions and curriculums. These provide great convenience for lifelong learning, as a kind of halfway between the first two methods, but as with social media, quality control of these courses can be questioned, accountability is low and fragmentation is high.

In this chapter I will be using my experience with Moodle, the open-source learning management system that I founded and still lead as CEO, as a window into best educational practices of today and what the future holds (Moodle n.d.).

\section{The Moodle Story}

I started working on Moodle (the Modular Object-Oriented Dynamic Learning System) in 1999, after seeing many of the problems that educators were having trying to educate students over the Internet, which was mostly available only in universities at that time. I had long experience of this, having grown up mostly in the desert regions of central Australia learning over shortwave radios and written correspondence. Employed as a full-time Internet consultant at my university, I was trying to empower the educators around me by replicating a variety of existing online tools such as forums, chats, wikis, quizzes, journals and a rich variety of content into a simpler, coordinated and safe framework that simplified access, organization and grading of students.

This tool had to provide an easy path for institutions to migrate their activities online - and it did this by using familiar terms and flexible structures that would allow educators to map their offline structures such as courses, department, roles and assessment processes to analogues online. Once these things were in one place, it would become a place for creativity and experimentation to find new techniques that were not even possible outside the computer environment.

In particular, I was interested in models that promoted both quality and scalability, so my research focused on the social constructivist approaches that treated all students as collaborators and created situations where students would learn from each other and with each other. The educator should not just be a repository of knowledge transmitting it to students, but a facilitator who is actively studying the students and creating new opportunities to help them learn together and to each create their own personalized learning.

Unfortunately, my university at that time had little interest in supporting the development of these tools internally, so I left the university and continued developing it as a full-time $\mathrm{PhD}$ student, and then later as a company (based in Perth and Barcelona) that continues to manage the Moodle project to this day.

The most important decision that I ever made during this - in my whole life, in fact - was to design Moodle as an open-source project. This decision not only 
removed barriers to entry for new users of the software, but it was fundamental to create an active community of users that could work with me on defining what the core software should be and for them to utilize this new space for their own education innovations. Our community is a learning community, growing together with the software, always exploring what is possible and feeding their suggestions back into the development process.

Now as of 2020, after constant evolution over 20 years, the project has grown dramatically on the sometimes-rough waters of the Internet. Moodle has spread internationally (organically, and mostly by word-of-mouth among communities) to be very widely used in all sectors everywhere in the world.

The clearest statistics are in the higher education sector, where over $67 \%$ of all higher education institutions use Moodle in some way, according to data collected by ListEdTech.com. However, there are countless users also in schools, workplace learning and development, global development projects with IGOs and NGOs, as well as many of the world's military organizations.

Overall, as of August 2020, as you can see on stats.moodle.org, there are over 160,000 registered sites worldwide (in every country), with over 220 million users using hundreds of languages for teaching and learning. Over 330 of those sites have over 100,000 students, and 7 sites have over 1 million users each. These significant statistics reflect a great responsibility that the Moodle project has to educators in the world.

Thousands of developers globally have contributed voluntarily towards the project as well as to the development of Moodle core itself. There are over 1,700 separate software projects based on Moodle (see moodle.org/plugins) that extend the core platform with integrations and innovative new features I never imagined, such as machine learning bots and many types of gamification. Few of these developers and collaborators have been paid directly by the Moodle company - they are usually paid by organizations who use Moodle in some way, and this collaboration is a side effect and a benefit of innovation and maintenance they were doing anyway.

The core work that is done to manage and steer all this activity is done by the Moodle company - we are sustained by a unique business model supported by a network of Moodle Partner companies around the world. Approximately 90 of these companies are certified by the Moodle company to provide services that help users of Moodle with things like hosting, consulting, training, development and more. Each of these partners pays Moodle a $10 \%$ royalty stream on their Moodle-related revenue, and that forms the bulk of the funding for the core work that helps everyone.

The most prominent advantages of open-source software such as Moodle are that it's easy to try out, and also easy for someone to host a production instance themselves. This is sometimes a security solution, when institutions are concerned about the privacy of their own data, but it may also just be a cost-saving measure, or a desire to heavily customize the installation or use it on a large scale. It is easy for developers and others to learn how to modify things and integrate with other 
local systems to build a bespoke solution. That said, it's also important (and often cost-effective) to outsource such services to those with experience, and that is why our Moodle Partner network is important. Typically, certified Moodle Partners, spread across the globe, can get your organization up and running to deliver digital and blended learning through a range of services including hosting, course design, training and ongoing implementation support to leverage the Moodle platform for delivering high-quality education.

Over the years, we've broadened the original Moodle LMS into a platform of separate products and services that address different aspects of online learning and the needs of our users: Moodle Apps provide the LMS experience for users in a mobile form, allowing better connection via notifications and integration with other apps; Moodle for Workplace is a whole package of plugins and improvements that make Moodle particularly useful for internal training, compliance and large enterprise environments; MoodleCloud offers SaaS solutions for those who need quick results for smaller projects; Moodle.Net is an entire social network for educators based around sharing and curation of OER; and the Moodle Educator Certification is a valuable certification addressing 22 core competencies for effective online teaching (https://moodle.com/mec).

Importantly, Moodle's values of openness, integrity, innovation and respect for education have never changed and neither has our mission: we are here to empower educators with the most efficient learning platform we can build. Our values and mission are an important part of the ecosystem in and around our open-source project, and they help our contributors work better together even when they're not being paid.

\section{Moodle for Sustainable Development}

Education is a huge part of sustainable development, or indeed, any major change and growth. Many organizations focused on capacity building use Moodle, including EU Devco Academy, various UNESCO agencies, Amref, World Bank, and World Vision.

There are a number of reasons why Moodle is seen as a good choice for such activities:

- $\quad$ First, the easy and safe availability of Moodle within all budgets means more transfer and pooling of knowledge and skills across institutions. Administrators and teachers often have some familiarity with Moodle from previous contexts, so it's easy to pick and get started.

- Second, as a common platform across institutions, it allows sharing of content and training at a high level beyond standards. Moodle has a well-developed backup/restore system that allows the sharing of complete courses. These simple files are easily shared by any means necessary, and there are many formal and informal methods of sharing, from email, to shared folders, to OER 
repositories. It also supports commonly used content standards like SCORM, AICC, IMS LTI, H5P and more as ways to reuse content in standard formats. This means that any existing content designed according to these standards will work in any Moodle site but also in any other LMS system, which helps provide some insurance against risk if systems change.

- Third, Moodle has been specifically designed for low-bandwidth environments that, while most obvious in many developing countries, are actually a reality in all countries (at different times and places). You can see this in the efficient web version of the interface which shrinks images and so on, but particularly (for students) via our mobile apps - which allow entire courses to be downloaded directly onto the device so that learning can continue even during periods when there is no Internet.

\section{Considerations for Implementing Moodle Effectively}

The tools that we build are designed to help achieve certain goals, but no tool will do the job on its own. Tools need to be guided by users, and so users need particular skills.

The most important thing is to plan the installation well. Moodle has thousands of features, and it's very often the case that many of them should be switched off in order to streamline the interface for users, and to reduce complexity and improve performance of the overall system. Technically, there are also plenty of decisions to make on servers, databases, networks and other factors. Finally, Moodle is very often only one part of a larger system with many components, such as authentication servers, student information systems, portfolio systems, video conferencing systems and so on. If it is decided to do this systems design and "tuning" in house, then there is plenty of documentation to support this (https://docs.moodle.org).

Once the system is in place, it is essential for success to make sure teachers are able to use it well. In the case of online learning, the goals and the skills can vary a lot, depending on the course, but here are some things you can do to help ensure a good result:

- To start, a course designer should start building a simple course, similar to the free course called Moodle Teaching Basics at learn.moodle.org. Find out how to upload a little content and to add some forums and maybe some assignments. Some early success in making their own course that looks good and achieves the basics will give educators confidence that they can do this and enable them to develop the attitude of an action researcher.

- Action research is simply a form of self-reflective enquiry undertaken by participants in social situations in order to improve the rationality and justice of their own practices, their understanding of these practices, and the situations in which the practices are carried out. As an action researcher, a teacher creates a process of constant self-improvement as they study their own course 
and make changes accordingly. This gives the teacher energy to try things and to explore the many resources available, such as Moodle documentation, community forums, help videos, conference recordings and more. Learning to teach better online is an ongoing process that never ends.

- One of the biggest factors, as mentioned earlier, is for the teacher (or other learning designer) to make sure that the content is suitable for the students and the location it is being used. In particular, for low-bandwidth environments, it is critical that the content be compact and easy to download. Longer-form content can be designed to be more modular and reusable, allowing it to be used in different contexts, and maintained with greater ease. Building content using standards like LTI (Learning Tools Interoperability) even allows courseware and learning tools to reside separately from the main learning management system - further increasing standardization, interoperability and reducing future risks.

- As a guide to many strategic elements that matter with online learning, it can help to look at some training or certifications. Moodle provides a Moodle Educator Certification that is based on 22 competencies defined by the European Union as DigCompEdu (https://ec.europa.eu/jrc/en/publication/ eur-scientific-and-technical-research-reports/european-framework-digitalcompetence-educators-digcompedu), covering areas in professional engagement, digital resources, teaching and learning, assessment, empowering learners and facilitating learners' digital competence. Figure 18.1 details how these fit together.

- Beyond the skills of teachers, it is vital that any implementation of a learning platform is funded appropriately and treated as an ongoing, living process of improvement. It is not possible to just set up the platform once, then ignore it for a long time and expect that it will be a success. Learning processes should be embedded into the processes of the organization, made part of the fabric of the organization, and frequently assessed and improved through feedback from teachers, students and other staff. It's a journey, not a destination!

\section{The Future of Open Education}

For the best future health of our nations and our world, to solve problems such as the United Nations Sustainable Development Goals (SDGs) and for any kind of democracy to really work well, we need generations of citizens who are educated about a broad range of topics, but particularly critical thinking and emotional intelligence. We live on a small planet, so they also need to be globally oriented, multiculturally aware environmentalists.

We need education more than ever, but we need to make it better than it is today to meet the expanded demand for lifelong learning and institutional capacity building. We will not fix world-scale problems by relying on people to learn 


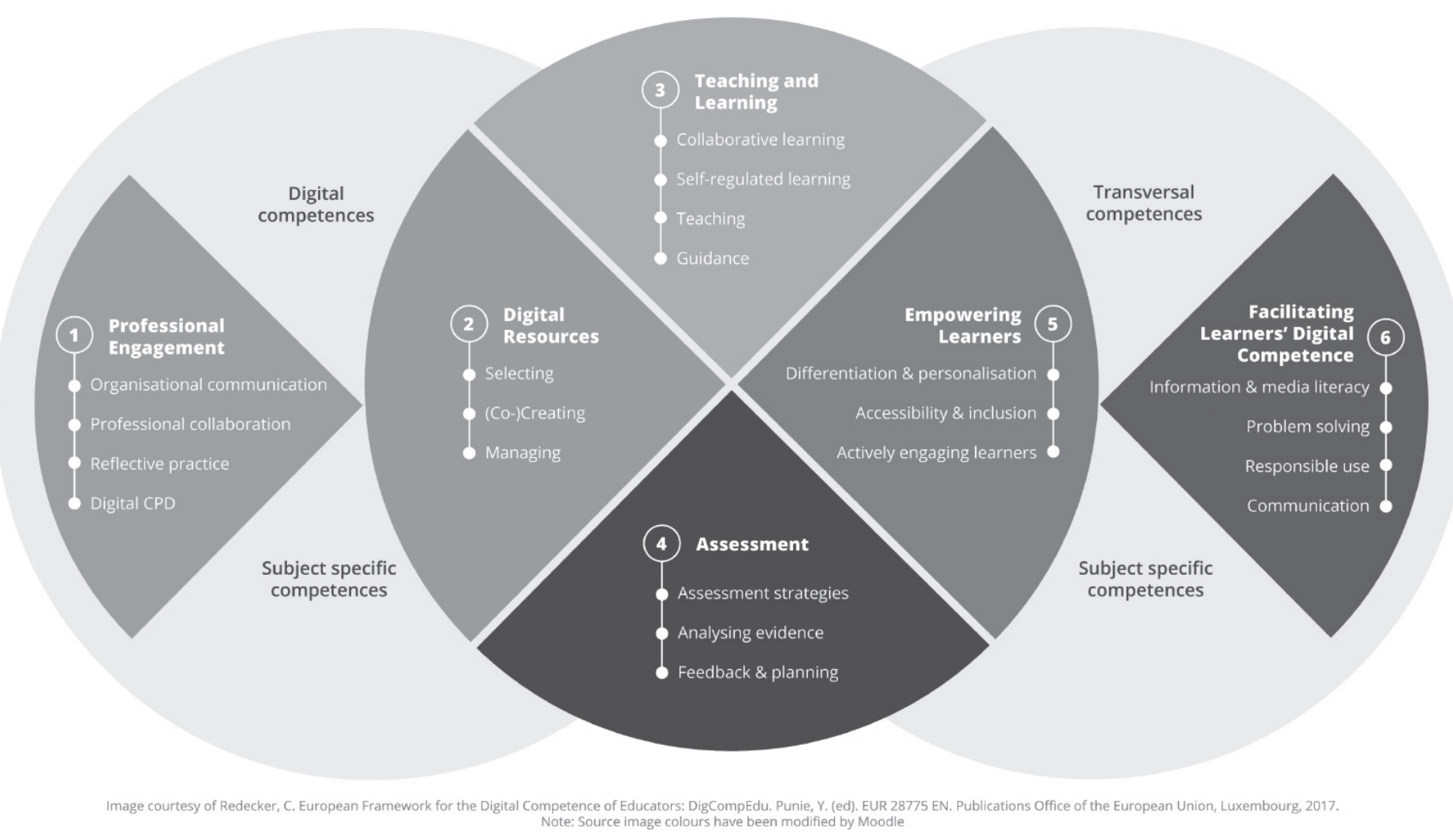

The 22 competencies defined by the European Union as DigCompEdu. 
about these things through face-to-face structured learning and via social media, nor will we fix them by making education expensive and hide information behind pay walls. Our education needs to be reinvented around the efficient, flexible technology that is now possible, in a way that serves education first and foremost and serves to improve our future on this planet.

"Our education needs to be reinvented around the efficient, flexible technology that is now possible, in a way that serves education first and foremost and serves to improve our future on this planet."

How do we do this? I see three main components to this future world platform:

\section{Open Educational Resources}

In 2019 UNESCO unanimously passed their historic OER recommendation, showing that the world is behind OER as a default mechanism for storing and reusing educational resources. Wikipedia has shown us all that an encyclopedia can be both high quality and open, and there are many more projects (including our own MoodleNet) that serve to stimulate the development and curation of a wider variety of high-quality learning content and resources. As we shift more and more to this mode, we increase equality and quality of the knowledge and learning that is freely available to all educational institutions. I believe that we can also be doing more here to include high-level goals such as SDGs into curriculums at every level.

Organizations such as Creative Commons, Open Education Global and others are centered on this kind of work.

\section{Open Education Technology}

The technology platforms that we use define the way we interact and, as more and more of our life is mediated online, the way we live. In general, our educational institutions must not be built on top of a risky and shadowy infrastructure of commercial greed or corruptible systems. The failure of so many "Big Tech" solutions has already shown us the problems inherent in approaches that force us to "rent" solutions with such conditions.

Open Educational Technology provides the way to achieve all the promise of current advances in technology such as AI, Blockchain and VR, in a way that both maximizes the possible sharing and efficiency of progressive discoveries, while also allowing the maximum flexibility in how it is implemented in any given local context, respecting the languages, cultures, risks and choices of local educational practices. 
Education requires constant adaptation and collaboration. To support this vision, a new organization called Open EdTech Global (https://openedtech. global/) is focused on certifying software projects that meet such criteria and that can form the basis of a common education infrastructure of the future. This group represents a group of developers and supporters from around the globe collaborating to build sustainable, long-lasting, open-source educational platforms that support online education with the highest quality, inclusivity and flexibility.

\section{Open Recognition}

While it is important to focus on wider educational issues in our systems (such as the building of citizens rather than just workers), it is critical to be able to track and recognize assessments of things that have been learned.

Currently, the world is lacking a standard way to capture our competencies and skills in a way that is truly transferable and can be used as part of automatable systems with a high degree of confidence. For example, if I demonstrate some skills while learning in one organization, that organization (or any individual) should be able to digitally sign a number of statements about my skills which I can easily share with anyone else who needs to see them. The weight and value of these signed statements should be tied to the reputation and traceability of the organization or individual who issued them to me.

One of the reasons this doesn't exist yet is because all known solutions depend on one company, or one website, and that will just not work in the long term because people won't trust it. A long-lasting solution to this depends on an open infrastructure being created that uses distributed technologies and digital signing techniques to create full trust in the system by all parties, some AI to parse the complex web of data, plus political weight behind it to enforce some standards in skills and competencies.

Pioneers in this area include Open Badges (https://openbadges.org/) and Open Recognition (www.openrecognition.org/).

It is good to see tangible progress in all these areas of Open Education, and I'm excited for the future and to be a part of helping it to happen.

\section{Reference}

Moodle (n.d.), Getting Started. Retrieved from https://moodle.org/ 